\title{
TÉCNICA E TECNOLOGIA SOB DIFERENTES CONCEPÇÕES DE TRABALHO: UM RELATO DE EXPERIÊNCIA EM UM PROJETO DE EDUCAÇÃO POPULAR PARA O ENSINO MÉDIO
}

\begin{abstract}
Beatriz V. Schneider-Felicio ${ }^{1}$
RESUMO: Este texto consiste em um relato de experiência que procura descrever a aplicação de uma aula que objetiva discutir com os alunos os conceitos de técnica e tecnologia inseridas em diferentes perspectivas culturais relacionadas ao momento histórico pós revolução industrial, como forma de contextualização e problematização. Os dados consistem nas anotações de campo e vídeos da aplicação da aula. A aula é preparada por um grupo docente multidisciplinar e aplicada em um projeto de Educação Popular que preza pela abordagem de ensino e aprendizagem por temas geradores. Os destaques do presente relato consistem nos momentos de interação entre professores e alunos na discussão sobre as diferentes concepções de trabalho das culturas católica e protestante e na construção dos conceitos de técnica e tecnologia durante a aula.
\end{abstract}

Palavras-chave: Educação popular; Temas geradores; Interdisciplinaridade; Contextualização.

ABSTRACT: This text consists of an experience report that seeks to describe the implementation of a class that aims to discuss with students the concepts of technique and technology contextualized in different cultural perspectives. The data consist of field notes and the class videos. The class is prepared by an multidisciplinary faculty group and applied in a project of popular education that values the teaching and learning approach for generating themes. The highlights of this report are the moments of interaction between teachers and students about different work conceptions from catholic and protestant cultures, and the concepts construction of technique and technology during class aplication.

Keywords: Popular education; Generating issues; Interdisciplinarity; Contextualization.

\section{INTRODUÇÃO}

Este relato de experiência tem sua origem em desafios enfrentados diariamente por professores e educadores que se encontram inseridos nas salas de aula da educação básica, tanto da rede privada quanto da rede pública de ensino, com a diferença adicional de dedicarem voluntariamente boa parte de seu tempo em um projeto de educação popular de um espaço não formal de ensino, cujo cenário será descrito na metodologia. Estes professores tem em comum a preocupação com as consequências do ensino disciplinar, tradicional e descontextualizado que vigora na prática daqueles que lecionam

1 Doutoranda em Ensino de Ciências (USP). Graduação em Química (USP) e Mestrado em Ensino de Ciências pela USP. 
no ensino básico formal, direcionado à formação dos estudantes apenas para a realização de exames vestibulares classificatórios, pontuais e excludentes como define Luckesi (2012).

Semelhantemente à preocupação desses professores, há muitos anos os documentos oficiais da educação brasileira vêm recomendando mudanças para a melhoria do ensino tradicional, contudo, estas ainda não fazem parte das discussões de trabalho entre coordenadores e professores, muito menos praticadas em aulas ministradas na grande maioria das escolas. Dentre outras recomendações dos documentos oficiais, as que são destaque na reclamação deste relato tratam da falta de contextualização e de interdisciplinaridade dos conceitos abordados pelos professores.

Nos PCNEM (BRASIL, 1999) foi proposta a subdivisão do Ensino Médio em três áreas: Linguagens, Códigos e suas Tecnologias; Ciências da Natureza, Matemática e suas Tecnologias e Ciências Humanas e suas Tecnologias. Além disso, também é proposto que o currículo do Ensino Médio deveria ser norteado por dois princípios centrais: interdisciplinaridade e contextualização. De acordo com o documento a interdisciplinaridade visa evitar a compartimentalização do conhecimento escolar e a contextualização visa dar significado a este conhecimento, sendo o trabalho e a cidadania os contextos valorizados pelos PCNEM de 1999.

Devemos admitir que se torna um tanto quanto delicado apropriarmo-nos do termo "interdisciplinaridade" apenas como um possível "anti compartimentalizador" do conhecimento escolar, diante de tamanha variedade de pesquisas, apropriações e concepções do termo dentro da área da Educação.

Como não é a intenção desse relato discutir a interdisciplinaridade sob diferentes pontos de vista, apenas nos posicionamos no sentido de concordarmos com Pontuschka (1993), ao afirmar que a interdisciplinaridade apresenta-se como uma metodologia em que se respeita a especificidade de cada área, procurando estabelecer e compreender as relações entre os conhecimentos sistematizados, ampliando o espaço de diálogo na direção da negociação de ideias e da aceitação de outras visões.

Cuidado semelhante é preciso tomar ao assumirmos o termo "contextualização" diante da área da educação e perante o direcionamento 
apontado pelos documentos oficiais da área no Brasil. Valorizar o trabalho e a cidadania como contextos é fundamental, no entanto, pelos princípios nos quais são baseados esse relato, a cidadania e o trabalho não devem ser os únicos contextos abordados, e além disso, é preciso posicionar-se perante suas concepções. No caso da concepção de trabalho, idealizamos a idéia discutida por Bauman (2001), do trabalho como vocação e fonte de existência, um esforço do indivíduo dirigido a atender as suas necessidades e bem estar, e os da comunidade. Ideia essa que, de acordo com o autor, para a quase totalidade da sociedade, foi extinta por meio da transformação da sociedade com a Revolução Industrial, quando ocorre a separação dos trabalhadores de suas fontes de existência ao passarem a trabalhar em funções compartimentadas das grandes fábricas e, ao longo dos séculos essa nova ordem social se perpetua e se adapta à atual sociedade de consumo, na qual o sentido existencial do trabalho para o indivíduo é torná-lo um consumidor em potencial. Logo, é preciso que, como mediadores do conhecimento, estejamos atentos se a nossa prática não está levando à formação de cidadãos individualistas e alienados, despreocupados com a sociedade com a qual se relacionam direta ou indiretamente.

Opinião adicional que nos leva a refletir sobre as colocações e direcionamentos dos documentos oficiais concernentes à integração do currículo é a de Lopes (2002), cuja reflexão sobre as propostas dos Parâmetros Curriculares Nacionais redigidos até o momento da obra, chama a atenção para o discurso da integração curricular através da interdisciplinaridade, o qual vem se legitimando de forma a institucionalizar relações de poder e construir processos de controle ou de regulação social.

Em complemento a estas posições pode-se dizer que a ideia de trabalhar em grupo multidisciplinar, dos professores envolvidos nessa experiência, acredita que para haver relações entre os conhecimentos e negociação de ideias em busca da contextualização e interdisciplinaridade, é fundamental o encontro, o planejamento antecipado, a conversa, a troca de experiências, o questionamento e o companheirismo entre os professores, buscando compartilhar os frutos dessas interações com os alunos, envolvendoos em um mesmo movimento. 
Acredita-se ainda que a interdisciplinaridade e a contextualização dos conceitos discutidos em aula, científicos ou não, são mais facilmente fomentados por meio de uma abordagem temática que preze por temas geradores articuladores das esferas científica, tecnológica, social, política, econômica, cultural e ética.

Em meio aos temas geradores, dos quais podemos citar alguns exemplos (Água, Direitos Humanos, Trabalho, Energia, Economia), busca-se envolver temas sócio científicos, principalmente temas sócio científicos controversos, partindo da premissa de que todo tema que envolve as esferas mencionadas no parágrafo anterior é sócio científico, porém, nem todo tema sócio científico é necessariamente controverso. Para a aplicação final em sala de aula, prioriza-se o uso de temas sócio científicos controversos, pois experiência do grupo e pelo estudo dessa literatura, constatou-se que a presença da controvérsia é um fator fundamental para a promoção do interesse, participação e envolvimento dos alunos com as situações propostas pela aula.

Os chamados temas sócio científicos controversos, ou temas controversos sócio científicos (TCSC), temas controversos, temas polêmicos ou temas contemporâneos, fazem parte de uma ampla variedade de perspectivas da abordagem CTS. De acordo com Levinson (2008), o estudo de TCSC foi estabelecido no currículo de ciências de escolas primárias e secundárias de muitos países industrializados, nos quais vem aumentando a conscientização da ciência como uma questão de política pública refletida pelo aumento da capacidade de posicionamento dos cidadãos frente à questões científicas em júris e conferências.

O uso dos temas controversos sócio científicos, como, alimentos geneticamente modificados, uso de células tronco, causas do aquecimento global, gestão global da emissão de gases poluentes, danos ambientais globais, dentre outros, implicam na discussão de questões contemporâneas polêmicas do mundo real situadas nas esferas política, econômica, científica, ambiental, cultural, ética e moral, a fim de levar o aprendiz a explorar conteúdos tradicionais e utilizá-los de forma contextualizada no entendimento e resolução do problema sócio científico proposto (SADLER e FOWLER, 2006). 
Um levantamento mais completo sobre a literatura internacional relacionada aos temas controversos sócio científicos pode ser encontrado em Reis (2007), onde o autor discorre sobre a extrema utilidade de seu uso, princípios nos quais são baseados, experiências de aplicações e as dificuldades de implantação de sua metodologia nas escolas. Concordamos com o autor e tomamos por base suas considerações, nas quais aponta aspectos necessários à preparação dos alunos para sua participação em processos avaliativos e decisórios sobre controvérsias sociocientíficas como:

a) um enquadramento de conhecimentos científicos indispensáveis à apropriação de conhecimentos mais pormenorizados sobre as questões em causa; b) conhecimentos metacientíficos sobre a natureza, as potencialidades e os limites da ciência; c) capacidades de pensamento crítico, tomada de decisões e resolução de problemas; d) atitudes e valores úteis à avaliação das dimensões ética e moral da ciência e da tecnologia; e e) vontade e confiança para lidarem com assuntos científicos. (REIS, 2007, p.127).

Vale lembrar que desde a resolução do Conselho Nacional de Educação (CNE, 1998), os PCN indicam a necessidade de desenvolver a "competência de emissão de juízos de valor", o que vem a concordar com os aspectos apontados acima, fortemente desejados para um trabalho que visa a aplicação de temas controversos sócio científicos.

Dentro do mesmo estudo supracitado, Pedro Reis traz diversos trabalhos internacionais cujas investigações evidenciam potencialidades da utilização das controvérsias sociocientificas em sala de aula, cujo impacto educativo promove a motivação, a pesquisa e o intercâmbio de informação, a reavaliação de atitudes individuais, sentimentos de auto-estima, apoio mútuo entre alunos e a apreciação dos conteúdos e experiências de ensino, desde que a aprendizagem seja estruturada de forma cooperativa. Por outro lado, também enumera diversos fatores observados em outros estudos, relacionados às dificuldades enfrentadas pelos professores em tornar esse tipo de atividade uma prática comum nas salas de aulas, como a falta de literatura e materiais adequados, discordâncias entre direção da escola e professores, dificuldades inerentes ao próprio processo de discussão, o qual exige a abdicação da postura autoritária do professor e a habilidade de controlar e avaliar atividades 
dessa natureza, tipos de exames nacionais propostos com ênfase na memorização, dentre outras.

Levinson (2008), ao propor uma teoria de abordagem curricular para o ensino de questões sócio científicas, problematiza o aumento de questões sobre avanços da ciência e tecnologia baseadas na mídia, as quais representam um perigoso problema ao simplificar as informações, sendo que na complexidade da ciência, as tecnologias emergentes são incertas e mesmo os experts podem discordar entre si. Logo, versões simplificadas de questões sócio científicas também dificultam sua inserção no contexto escolar, podendo gerar concepções alternativas. Portanto, o currículo e as atividades propostas devem ser cuidadosamente preparados e conduzidos.

Dentro da abordagem dos temas sócio científicos controversos este trabalho escolheu relatar o desenvolvimento de uma aula de ciências naturais contida no tema gerador "Trabalho", onde o tema sócio científico envolvia a construção dos conceitos de técnica e tecnologia ao longo da história, cuja controvérsia se localizava nas diferentes concepções de trabalho, técnica e tecnologia presentes em diferentes contextos sócio culturais de determinada época, no caso, as religiões católica e protestante no período da primeira Revolução Industrial. O objetivo central desse trabalho consiste em relatar como se deu o processo de discussão sobre as diferentes concepções de trabalho das culturas católica e protestante e da construção dos conceitos de técnica e tecnologia pelos alunos durante a aplicação da sequência didática preparada por um grupo multidisciplinar de professores, bem como refletir sobre o processo buscando propor sugestões de melhorias para futuras aplicações.

O conceito de tecnologia está associado a cada uma das áreas estipuladas pelos PCNEM, como já mencionadas anteriormente, e o mesmo se reflete nas Diretrizes Curriculares Nacionais para o Ensino Médio (DCNEM). No caso da área de Ciências Naturais, Matemática e suas Tecnologias, foi associada, por sua vez, a grande competência de "investigação e compreensão", competência entendida, de maneira simplificada, como capacidade humana complexa. A presença da tecnologia em cada uma das áreas foi justificada como uma tentativa de aproximação da escola ao mundo moderno e à compreensão dos processos produtivos. Esta justificativa e a 
proposta de se trabalhar as áreas de modo interdisciplinar e contextualizado, sugere que à tecnologia seja atribuído 0 papel de promover a interdisciplinaridade e a contextualização.

No entanto, a própria literatura da pesquisa em Ensino de Ciências que busca maneiras de introduzir a tecnologia ao ensino e aprendizagem na área das ciências naturais, relata dificuldades encontradas nesta busca, principalmente quanto às concepções alternativas dos professores da escola básica a respeito do conceito de tecnologia e quanto à indefinição de referências dos documentos oficiais sobre qual perspectiva teórica deve-se adotar para sua transposição, sendo que entre as próprias disciplinas das ciências naturais existem divergências quanto à ideia de tecnologia (RICARDO, CUSTÓDIO, REZENDE, 2007).

Para os fins da sequência didática aplicada neste relato adotamos como referência conceitual o que os mesmo autores chamaram de "uma das dimensões da tecnologia":

[...] a de um empreendimento humano entendido como o estudo do artificial e produtor de saberes específicos, ainda que tenha uma estreita relação com os saberes científicos e que, com efeito, constitui uma de suas características principais. (RICARDO, CUSTÓDIO, REZENDE, 2007, p. 2).

Em outras palavras e em complemento a esta referência, concordamos com a concepção de tecnologia como um campo de produção de conhecimento, possuidor de sua própria epistemologia, e é com essa premissa que foi pretendida a construção dos conceitos de técnica e tecnologia com os alunos em sala de aula.

\section{METODOLOGIA}

O contexto metodológico no qual este relato foi elaborado se passou em uma turma de alunos de um projeto de educação popular denominado Conexão, vinculado ao Centro de Investigações e Metodologias Educacionais Alternativas, sediado pelo Laboratório de Ensino de Biologia do Depto. De Biologia da Faculdade de Filosofia, Ciências e Letras de Ribeirão Preto.

O grupo Conexão, como é conhecido, investe seus esforços na formação de cidadãos que, de algum modo, estejam desfavorecidos sócio 
economicamente e por isso não tenham condições de se preparar para exames vestibulares e outros concursos que cobrem os conhecimentos da educação em nível médio. No entanto, a formação que o grupo prioriza vai além da preparação para exames classificatórios. Visa principalmente a formação do cidadão crítico, participativo, observador, que saiba se posicionar humanamente diante de injustiças sociais, de decisões políticas, no seu posicionamento ético, entre outras questões nas quais o conhecimento científico com o qual tem contato nas aulas, possa ajudá-lo a esclarecer e a se posicionar. Visa também formar o cidadão que saiba conduzir sua formação e busca de conhecimento de maneira contínua e autônoma, conhecendo diversas formas de buscar e sistematizar o conhecimento para além das aulas frequentadas.

As aulas, apesar de incluírem os conteúdos tradicionais do currículo do Ensino Médio, são preparadas e aplicadas de forma diferenciada de como ocorre nas instituições formais, pois são elaboradas de forma contínua, em reuniões semanais nas quais todos os professores das diversas disciplinas se reúnem para discutir como os conteúdos serão construídos em cada aula, de maneira interdisciplinar e contextualizada dentro dos temas geradores centrais e dentro de temas sócio científicos controversos propostos através de situações problema a serem estudadas, discutidas e, se possível, solucionadas pelos alunos, visto que nem todos os temas sócio científicos controversos chegam a um acordo ou solução, importando apenas, em alguns casos, a compreensão do processo. A aplicação de uma aula conta com a participação de, ao menos, dois professores de áreas distintas que tenham preparado a aula em conjunto. A aula do dia tem ênfase em uma das áreas curriculares do Ensino Médio e é complementada, na medida do possível, com conteúdos das demais áreas, também inseridos na situação problema elaborada com antecedência. Uma aula tem a duração de três horas, com um intervalo de vinte minutos e não necessariamente se encerra no mesmo dia, podendo ser continuada até se encerrarem os conteúdos ou estes podem ser retomados em outra aula em que encontre contexto.

A aula é redigida em forma de uma sequência didática e passa a integrar o material confeccionado pelo grupo, o qual é impresso e entregue aos alunos para fins de leitura, anotações e acompanhamento da aula. Em complemento a 
este material, os alunos também são levados a consultar livros didáticos e de literatura, vídeos, e sites de fontes confiáveis indicados pelos professores.

A parte da sequência didática correspondente à aula que se pretende relatar neste trabalho segue abaixo, assim como é apresentada aos alunos no material impresso. Esta aula consiste na segunda aula que enfatiza a área curricular de Ciências Naturais, dentro do tema gerador "Trabalho" ministrado aos alunos durante o mês que aborda esse tema, por isso "aula 2". Consiste também na primeira parte de uma sequência didática composta por dois dias de aplicação, com duração de três horas de aplicação por dia, por isso "parte 1". Vale ser feita a consideração de que os alunos, nesta fase de abordagem do tema trabalho, estudaram sobre máquinas térmicas no contexto da primeira Revolução Industrial anteriormente, na aplicação da "aula 1" com ênfase em Ciências Naturais.

\section{AULA 2 (Parte 1) - CIIÊNCIAS NATURAIS}

\section{O trabalho perante diferentes concepções religiosas}

\section{Introdução}

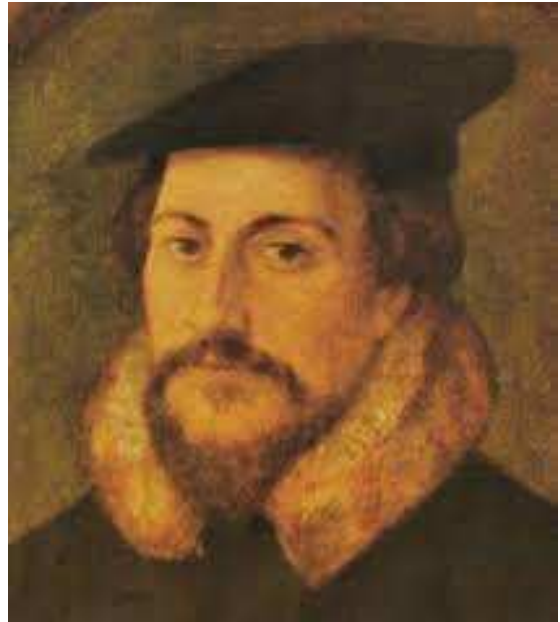

JoãoCalvino

http://iprodigo.com/resenhas/joao-

calvino-um-coracao-pronto-e-sincero.html
Como já visto em aulas anteriores, para alguns povos da antigüidade, o trabalho se referia a algo impuro, indigno e desprezível. Não era uma atividade digna do homem livre. Aos escravos cabiam as tarefas diárias, ou melhor, o trabalho. $\mathrm{Na}$ Idade Média, o trabalho era visto como servidão, na qual os homens se punham sob a proteção dos senhores da terra, prestando-lhes homenagens. Cabe aqui ressaltar que a atividade produtiva era semelhante às da Antigüidade grega (ou Clássica). O que diferenciava uma da outra é que, na Idade Média, o trabalho era visto como um bem. Árduo, mas um bem. $O$ trabalho só vai receber um aspecto diferente e inovador com João Calvino e sua Reforma protestante. Para João Calvino, o sucesso no trabalho e nos negócios deveria ser conquistado por meio de uma nova ética religiosa do trabalho.

Calvino justificou atividades econômicas até então condenadas pela Igreja, uma vez que, segundo suas concepções, todo trabalho, desde que feito com honestidade e sobriedade, era agradável a Deus, e somente os predestinados conseguiam vencer na vida. $O$ trabalho era uma bênção divina.

Tendo sido criado no mundo dos negócios, Calvino deu impulso considerável ao nascente capitalismo porque comerciantes, banqueiros, industriais, armadores e outros descobriram que também trabalhavam pela glória de Deus. O calvinista provava 
a si mesmo que era uma boa pessoa, que obtinha sucesso como bom cristão, trabalhando muito e seguindo sempre os melhores princípios éticos.

Não era a sua ação, mas sim a ação de Deus, que lhe mostrava que ele estava no bom caminho.

Sociólogos como Max Weber e Ernest Gellner analisaram a teoria e as conseqüências práticas dessa doutrina e chegaram à conclusão de que os resultados são paradoxais.

Em parte, explicam o precoce desenvolvimento do capitalismo nos países onde o calvinismo foi popular, sobretudo na Holanda, na Escócia e nos EUA.

As idéias de Calvino ajudaram em medida o desenvolvimento do capitalismo, pois diziam que o predestinado deveria poupar, ao contrário do catolicismo, que condenava até a usura. Esse precoce desenvolvimento pode ser explicado pela concepção de que, para o calvinista, a riqueza poderá ser um sinal de que aquela pessoa está entre os escolhidos de Deus. Ou seja, se um calvinista tem muito dinheiro, é um sinal de que Deus o escolheu para ser salvo.

Por causa das idéias da doutrina calvinista, os holandeses, os escoceses e os americanos ganharam a fama de serem sovinas, pouco generosos, interessados apenas no dinheiro.

$\mathrm{Na}$ vida moderna essas características são adquiridas em qualquer cultura, mas nos tempos da Reforma Protestante, o calvinismo instituiu uma nova e revolucionária forma de relação com a riqueza e com a organização políticoadministrativa de alguns lugares da Europa, vindo ao encontro dos anseios da burguesia.

(Texto "Concepção contemporânea do trabalho". Em: http://xa.yimg.com/kg/groups/18315139/1506082020/name/aula 03 sociedade e organizacoes.pdf. Adaptado.)

\section{0 problema}

No decorrer da história o trabalho gerou técnicas e tecnologia, como ocorreu com o desenvolvimento das máquinas térmicas na Revolução Industrial, que possibilitaram o aprimoramento e evolução do trabalho, porém, dependendo do lugar, do país, da cultura local, a evolução das técnicas pode ser tardia ou mesmo não ocorrer de maneira original, ou seja, a nova técnica é importada de outro país.

Imagine que em determinado momento da história, dois trabalhadores que possuem a mesma função (abastecedor de carvão de uma máquina a vapor), um inglês e um português, cada um vivendo em seu respectivo país, utilizam a mesma técnica para abastecer a máquina: carregam sacos de carvão nas costas, trazem para perto da fornalha e com a ajuda de uma pá, jogam o carvão dentro da fornalha.

Partindo do princípio de que cada trabalhador pertence a uma vertente religiosa diferente (consulte o texto anterior), cada qual com sua cultura e concepção sobre trabalho, proponha uma breve história para cada indivíduo, nas quais ocorressem diferentes caminhos para o aprimoramento de uma mesma técnica. Como seria o caminho de desenvolvimento da técnica pelo inglês? E pelo português? Proponha as histórias e justifique-as. Você pode optar por escrever e ler a história para os colegas ou contá-la.

- Outras religiões podem ser pesquisadas e incluídas, por exemplo, como seria essa história para um trabalhador indiano?

- Após a exposição da sua história faça uma breve discussão com os colegas e professores sobre a diferença atual das economias da Inglaterra e de Portugal. Inclua um desfecho atual para sua história com essa discussão e uma conclusão de como a cultura influencia o desenvolvimento de um país. 
- Leia o texto exposto nos materiais de apoio desta aula com o auxílio de um dicionário e do professor. Em conjunto, discutam sobre a diferença entre técnica, tecnologia, objeto/aparato tecnológico, ciência, ciência básica e ciência aplicada, a fim de diferenciá-las.

\section{Materiais de apoio necessários}

- Livros de História que abordem a reforma protestante;

- Trecho do texto "A Tecnologia como referência dos saberes escolares: perspectivas teóricas e concepções dos professores" adaptado, da Revista Brasileira de Ensino de Física, v. 29, n. 1, p. 139-141, (2007). Em: www.sbfisica.org.br

\section{4. Índice de conteúdos conceituais da aula}

- Ciências Humanas - Reforma protestante e concepções de trabalho.

- Ciências Naturais - Ciência, Tecnologia e círculo de conceitos.

Esta aula, preparada pelo grupo multidisciplinar de professores, foi redigida pela autora do presente texto, professora de química, e aplicada por dois professores das áreas de biologia e de física. Esta aplicação foi filmada por estes professores e assistida pela autora, a qual pretende compartilhar a experiência destacando algumas observações.

Os diálogos foram transcritos na íntegra, porém não em sua totalidade, priorizando as falas que mais se relacionam aos objetivos de discutir os elementos da reforma protestante, das concepções de trabalho e dos conceitos de técnica e tecnologia. As reticências eventualmente utilizadas omitem falas desnecessárias ao entendimento da discussão como um todo, ou repetitivas.

\section{RESULTADOS: RELATO E OBSERVAÇÕES DA APLICAÇÃO DA AULA}

No dia da aplicação compareceram cinco, dos oito alunos que normalmente frequentam $\circ$ grupo. Logo, não queremos aqui fazer comparações com o ensino que acontece na escola formal, o que não nos impede de termos a pretensão de aplicar esse tipo de metodologia em turmas maiores e mesmo na escola.

A primeira etapa da aula foi a leitura individual do texto introdutório "Concepção contemporânea de trabalho", e a partir dessa leitura, os professores conduziram sua discussão levando os alunos ao problema proposto. 
Chamarei de professor 1 e professor 2 e os alunos de aluno A, aluno B, aluno $\mathrm{C}$, aluno $\mathrm{D}$ e aluno $\mathrm{E}$ para preservar a identidade de todos.

Primeira etapa: as concepções de trabalho, reforma protestante e Revolução Industrial.

O professor 1 chama os alunos, nesta primeira etapa, a refletirem sobre como a concepção de trabalho da sociedade mudou no período entre antes e após a Revolução Industrial, retomando alguns assuntos já discutidos em aulas anteriores, e em seguida pergunta:

Professor 1: "De que maneira, então, a noção de trabalho foi mudando? A industrialização mudou todo processo, sim, mas as pessoas são diferentes em determinados locais. O que vocês viram aqui pelo texto? O que vocês entenderam da idéia aqui dessa introdução? O que pode estar influenciando nessas concepções mesmo após a Revolução Industrial? Ele fala de um personagem real aqui, mostrou aqui a foto. Quem é essa pessoa? O que vocês conseguem pensar disso?"

Aluno A: "Pelo que eu entendi, (inaudível), na época da igreja católica, a idéia católica era outra...eu entendo assim, moço: ele é ganancioso, ele fala de um princípio diferente. Quanto mais bem o cara tinha, quanto mais ele trabalhasse, mais próximo do céu ele tava. A igreja católica não achava isso, entendeu? Fala também da divisão da igreja católica quando surgiu a evangélica.

Aluna B: "Protestante."

Aluno A: "Protestante." Foi nessa época. O princípio dele era protestante, contra a religião católica. O princípio dele era o capitalista, né?"

Professor 1: "Dele, quem, você diz?"

Aluno A: "João Calvino."

Professor 1: "João Calvino era o quê, então, aí na história?"

Aluno 1: "João Calvino foi quem deu início ao capitalismo, não é?"

Nesse momento os professores 1 e 2 relembram sobre o surgimento do capitalismo a partir da queda do feudalismo, tentando mostrar o porquê não se pode responsabilizar apenas uma pessoa pelo surgimento de todo um sistema de produção. A partir disso, a aluna B se manifesta, relembrando as concepções de trabalho desde a escravidão:

Aluna B: "Vem da concepção também, de que as pessoas tinham, de trabalho. Ele começa o texto falando que alguns povos da antiguidade tinham o trabalho como algo impuro. Quem exercia,...é,...é, esse tipo de atividade era os escravos."

Professor 1: "Por que eram os mais impuros, né?" (faz sinal de "entre aspas")

Aluna B: "Eram os impuros"... 
Professor 1: "Por que eram os desalmados, aqueles que não eram, nesse, nesse momento, nem considerado humanos. Eles eram ferramentas."

Aluna B: "E é aí que João Calvino veio com a idéia de que não! $O$ trabalho, ele vem de Deus. O trabalho é um dom. Quer dizer, ele vem de Deus. Você tem a capacidade de realizar trabalho, é porque você tem, pelo que ele fala, aquilo que vem de Deus. Então não é impuro, é uma bênção você poder realizar um trabalho."

Professor 1: "E aí esse argumento começou a agradar, né?"

Aluna B: "Agradar, porque, as pessoas começou, ahn, você começa a trabalhar mais, você produz mais..." pessoas?"

Professor 1: "E quando você fala "pessoas", principalmente quais

Breve silêncio.

Professor 1: "Os burgueses, né? Então você tinha burgueses que trabalhavam no comércio. $E$ eles trabalhavam. $E$ quanto mais eles trabalhavam, mais eles comercializavam, mais eles enriqueciam. Num contexto de uma igreja que diz: olha, mais valia, o que que é mais valia? Lucro, né? É pecado! Isso aí é pecado. E é impuro. Então, quer dizer, então eu sou excomungado. Como burguês. Então, achar um discurso que fala: você também é de Deus porque trabalha, isso te engrandece, foi favorável naquele momento, né? E isso co-produz argumentos."

Aluna B: " $E$ isso (inaudível) com o capitalismo, porque o capitalismo grosso é isso. Não que ele funde o capitalismo, mas é uma vertente muito boa, favorável a isso."

Podemos perceber, neste primeiro conjunto de falas, a relação que os professores procuram fazer entre as culturas religiosas divergentes e as respectivas concepções de trabalho, bem como o processo de transição do modo de produção para o capitalismo.

Num primeiro momento, é notável que o aluno A, apenas com a leitura do texto introdutório, acabaria por concluir que João Calvino foi o fundador do protestantismo e do capitalismo, o que sugere a readaptação do texto e mostra a importância da intervenção dos professores, de maneira a conduzir o diálogo até a conclusão da aluna $B$, de que João Calvino não é o fundador, mas um influente, ou, influenciado pelo capitalismo, conclusão que considero extremamente importante para que os alunos não criem uma concepção alternativa sobre a história da reforma protestante e sobre o surgimento do capitalismo.

Após esta discussão, os professores prosseguem discutindo sobre diferentes concepções de trabalho nos dias atuais, fazendo comparações entre trabalhadores braçais que trabalham oito horas por dia e outros perfis, como 0 de um escritor, que, hipoteticamente, pode passar semanas sem trabalhar e 
semanas escrevendo quatorze horas por dia, o que gerou discussão sobre diferentes tipos de trabalhos e julgamentos, na sociedade contemporânea. Não serão detalhadas estas falas aqui, pois aquelas concernentes ao objetivo principal da aula serão priorizadas. Até aqui, o objetivo foi preparar um contexto para a discussão sobre os conceitos de técnica e tecnologia. Consideramos como contexto a chegada do capitalismo, a Revolução Industrial e as diferentes religiões, católica e protestante, que geraram concepções controversas de trabalho. Assim, forma-se o cenário para que se prossiga a discussão.

Segunda etapa: técnica e tecnologia perante diferentes concepções de trabalho.

A segunda etapa da aula, item 2 da sequência didática, consiste na proposição da situação problema, a qual foi lida junto aos alunos, explicada e delegada. Conforme a proposta do item 2 da sequência didática, dois grupos de alunos foram formados: um representando o trabalhador que vive em uma sociedade católica e outro grupo representando o trabalhador da sociedade protestante, este, formado por duas dos cinco alunos. Esperou-se que os grupos fizessem as respectivas versões hipotéticas sobre o caminho que cada trabalhador tomaria quanto ao uso da técnica e o possível desenvolvimento da tecnologia, e que ao final dessas versões, os alunos projetassem essas histórias ao presente e refletissem sobre as diferenças de desenvolvimento econômico atual entre Inglaterra e Portugal.

Para alimentar as histórias a serem contadas, os professores pediram para que cada grupo pesquisasse nos livros didáticos de história, disponíveis em sala, sobre as características das respectivas religiões no contexto da reforma protestante. Dessa forma, foi dado um tempo para que os grupos estudassem sobre os conteúdos de história, um pouco mais a fundo.

Passado o tempo estipulado, em torno de vinte minutos, o primeiro grupo a se manifestar foi o que representava o trabalhador português, inserido numa sociedade católica.

Aluna C: "A gente viu que a reforma protestante aconteceu por que...(pequena pausa)...a igreja que tinha o poder, ahn, é, era maior o poder da igreja do que até mesmo dos reis,..."

Aluna B: "Da monarquia" 
Aluna C: “...e aí foi criando revolta porque a burguesia tava tentando se desenvolver com o comércio e tudo, só que a igreja católica, ela não deixava fazer nada, ela criticava falando que o lucro era pecado. Então, tipo, isso, é, foi o que causou uma revolta muito grande porque como é que os burgueses iam lucrar, ganhar dinheiro, trabalhar e ganhar dinheiro, se num..., não só os burgueses, mas todos se não tinha como lucrar, então ia trabalhar só por obrigação mesmo, só pra...ah, por causa disso. E aí, ah, é, e aí, a igreja (inaudível) defendia o custo preço, que era isso daí. E tem um fator aqui também que influenciou, foi que o clero, o clero não, o pessoal da igreja, eles vendiam indul..., indulgências, que era, tipo, ce paga pra ser perdoado e isso ia contra o que eles ensinavam, do perdão e tudo. Foi um fator que influenciou."

Professor 1: "Que eles ensinavam, quem você diz? A igreja vendia as indulgências e aí os protestantes, eles eram contrários a isso?"

Aluna C: "É."

Professor 1: "Ah, tá."

Aluna C: "Eles eram contra."

Professor 1: "E aí se vocês fossem, por exemplo, esse trabalhador, com essa concepção católica e tal, vocês acham que esse contexto influenciaria em como pensar essa função, por exemplo? Porque dentro de uma fábrica, eu tenho esse cara que tá lá com a pá jogando carvão ali dentro e eu tenho o cara que é chefe ali, eu tenho várias funções. Esse trabalho lá, dezoito horas, jogando, aquele calor, respirando fuligem, ali com aquela, todas aquelas condições insalubres que a gente diz, como você, como patrão poderia justificar, por exemplo, essa função? Patrão católico?

Aluna B: "Ah, como se esse operário, ele merecesse aquilo, ele fosse merecedor, tipo assim, ele, a condição dele era fazer aquilo. Porque ele era impuro e o trabalho dele teria que ser aquilo. Ele era pecador.

Nesse momento tem início uma discussão sobre quem poderia ser esse trabalhador. Exemplos hipotéticos como um escravo, alguém condenado por um crime, dentre outros, com a conclusão de que o patrão não teria nenhum peso na consciência de manter aquele trabalhador naquelas condições.

Professor 1: “...Então quer dizer que na lógica de vocês esse trabalhador poderia ser mantido tranquilamente utilizando, por exemplo essas pessoas que merecem estar ali...isso bate totalmente com o contexto histórico que vocês acabaram de mostrar...E vocês (se dirigindo para o outro grupo), como é que era esse conceito no protestantismo?"

Percebe-se que até o momento o grupo não vinculou a concepção católica de trabalho com o possível desenvolvimento de técnica e tecnologia. $O$ que foi colocado continua ainda na descrição sobre a concepção de trabalho no contexto da reforma protestante, o que já consideramos um exercício de contextualização feito pelos alunos, com suas palavras. Talvez a própria concepção de trabalho descrita pelo grupo não tenha os levado a pensar sobre a presença ou mesmo a ausência da técnica e tecnologia. Logo, esperávamos 
que com a descrição do grupo representante dos protestantes, esses termos começassem a aparecer para poderem ser desenvolvidos pelos professores.

Aluna D: “...(inaudível) calvinismo. A idéia deles era visionária. Até então eles só conheciam as doutrinas católicas, que..."

Aluna E: "Martinho Lutero."

Aluna D: "Martinho Lutero também era católico e tinha uma visão crítica do que ele tava vendo acontecer naquela época e conseguiu perceber que a igreja tinha uma visão que só os nobres tinham a salvação porque quem praticava os serviços na época eram os escravos. Os escravos pela situação que eles tinham, porque eles não tinham acesso, talvez, àquela..." (pausa).

Aluna E: "É que assim. É...é que a gente colocou assim: catolicismo versus protestantismo. É..., por quê? Porque na verdade, assim, teve essas duas vertentes, né, de o catolicismo ter suas classes sociais, essa divisão, e de que se a pessoa nasce nobre ela vai morrer nobre e ponto final. E de que...

Professor 1: "E isso era do catolicismo?

Aluna E: "Não, na verdade era da época, né, que todos os nobres eram católicos. E o protestantismo ele veio, pelo, pela idéia que tinha de Martinho Lutero, pra tentar, assim, reverter isso e mostrar que todo mundo tinha direito e de que a salvação poderia ser pro nobre e pro pobre, né, então podia ser pra aquele mais digno e o indigno, como era de, como era visto antes ... e o trabalho que era visto pelo catolicismo como usúria, ... no protestantismo mostra que ele era um dom ... O protestantismo, ele é formado por pessoas burguesas, não por pessoas da nobreza, nobre, então assim, é..., a pessoa que morava no burgo, que era mestre de uma técnica, começa fazer uma fábrica, e começa a ter a técnica e o dinheiro pra investir, ele tem a pensar em investir mais e mais na fábrica dele. E ele, e ele nunca chegaria a ser um nobre...e o catolicismo barrava muito isso...e o protestantismo veio pra mostrar que ... o trabalho era um dom, veio pra mostrar outras direções pras pessoas...

Professor 1: “... Você acabou de usar a palavra técnica. Então o cara tem lá o recurso capital, ele investe na, numa determinada tecnologia industrial, e as pessoas trabalham, e eu tenho que pensar em cada vez que isso me gere mais capital pra que eu possa investir e pra que eu possa acumular mais capital e ter a chance der ser uma pessoa com vários acessos e tal. Aí você usou a palavra assim: quanto mais ele trabalha, mais ele desenvolve essa técnica, foi alguma coisa assim?

Aluna E: "Isso."

Professor 1: "Tá, então como é que eu penso nisso, é..., eu penso num cara assim, pegando o carvão com a pá (faz o gesto) e jogando aqui,...com essa mentalidade que você acabou de me falar, a perspectiva do trabalhador seria a mesma, ou não? Vocês pensariam em outra coisa...como vocês pensam, se vocês tivessem a mesma função na fábrica?"

Aluna D: "Ah, com o tempo, com o crescimento da fábrica, aquela função seria exercida de outra forma, por causa da tecnologia, não seria mais manual, mas sim com uma máquina que fizesse todo trabalho daquela pessoa, tirasse (inaudível), põe no forno, ou seja, a vida daquela pessoa não seria mais em função ... desse trabalho repetitivo todos os dias, seria por outro processo." 
Professor 1: "Olha que interessante. Existe, mas nessa perspectiva você tem que continuar nos esforços pra que ele não exista. Ser substituído. E ali (aponta para o outro grupo) não, e o pecador fica ali."

Aluna D: "Quer dizer, na concepção protestante, do protestantismo aí, logo com o tempo não existiria mais."

Professor 1: "Ninguém merece tá ali, você pode colocar eles em situações melhores."

Aluna D: "Mas querendo ou não, alguém vai fazer."

Professor 1: "Mas até que se crie uma máquina que substitua?"

Alunas D e E: balançam a cabeça concordando.

Professor 1: Então são duas visões, né? Ou não? Qual fábrica dessas deve se desenvolver mais, hein?

Aluna B: (inaudível)

Professor 1: "No caso a deles?" (aponta para o grupo dos protestantes)

Aluna E: "Porque, na verdade, se o cara trabalhar lá, de colocar lá o carvão, ... e tivesse a tal máquina que fizesse essa função, ele podia atuar, de, de monitorar essa máquina, ou trabalhar dentro da fábrica fazendo outra coisa, criando uma técnica, sendo o criador, aprendendo alguma coisa né, de alguma técnica e tal."

Nesse momento, os professores levam os alunos a discutir sobre 0 desemprego causado pela substituição dos homens por máquinas. Os alunos apresentam uma idéia que concorda com o aspecto negativo da perda do emprego para uma máquina, ponderando algumas vantagens que tiram 0 trabalhador de condições precárias. Após essas ponderações o professor introduz uma das questões sugeridas no problema da sequência didática:

Professor 1: "Não limitando a um único fator, mas pensando nesse fator, como vocês comparariam a industrialização na Inglaterra, Alemanha, né, nesses países da Europa, do norte da Europa com a dos países ibéricos, no caso, Portugal e Espanha, a industrialização é a mesma? Foi a mesma? Qual é mais fortemente industrializado, em termos de desenvolvimento econômico...?"

Aluna B: "A Inglaterra."

Professor 1: "A Inglaterra" (balança a cabeça concordando). Você (se referindo a ele mesmo) tá querendo dizer que a Inglaterra é mais industrializada porque eles são protestantes? Não, nós não estamos dizendo que é a única causa. Estamos trazendo uma idéia pra vocês pensarem em algo que talvez vocês nunca tenham pensado. Que o indivíduo, quando ele encara e vida e quando ele concebe algo, isso influencia no que ele faz. Se a gente pegar uma sociedade inteira, que tem uma determinada cultura e uma determinada concepção, a maneira de encarar a vida e de fazer é diferente...Pegar, por exemplo, os indianos, uma outra cultura..."

Nesse momento ocorre uma conversa sobre como o trabalho é visto de uma maneira diferente na cultura indiana, também influenciado pela religião. Quando o professor retorna para as culturas européias trabalhadas nos grupos, 
faz também uma comparação do trabalho, na concepção católica discutida anteriormente, com o trabalho de homens presos na atualidade, como uma espécie de punição.

Dando segmento a sequência didática e retomando a questão da técnica e tecnologia, o professor 1 propõe aos alunos que tentem diferenciar técnica de tecnologia.

Professor 1: "Criar uma máquina para substituir o homem é uma questão de técnica ou tecnologia? (breve silêncio) O que seria a técnica, então?"

Aluna E: "Quando surge da técnica, né? De você saber fazer, é..., tem um exemplo assim: se você tem um cara, que ele faz sapato, ele vai demorar mais pra fazer esse sapato, do que uma fábrica que vai gastar vinte minutos, prum cara que demoraria, sei lá, vinte horas. Então assim, ele tem a técnica, só que, a partir dessa técnica ele pode criar uma tecnologia, que seria por meio das máquinas pra poder aumentar a produção."

Professor 1: "Quer dizer, então eu posso ter técnica tanto na indústria quanto no artesão."

Professor 2: "A técnica é o saber fazer? É isso?"

Aluna E: "Isso."

Professor 1: "Então daquela outra aula, comparando: o macaco que pegava a pedra pra quebrar o côco, ele tinha técnica?"

Alunas B e D: "Tinha."

Professor 1: "Ou era tecnologia?"

Aluno A: "Não." E balança a cabeça em sinal positivo de que estava entendendo.

Professor 2: "Como que ele ia desenvolver uma tecnologia, então? Será que ele conseguiria? Dá um exemplo."

Aluna E: "Ele com um impulso, quebraria mais..."

Professor 1: "Mas aí é um aperfeiçoamento da técnica, que vocês tão falando, é um aperfeiçoamento do saber fazer ou aí é tecnologia?"

Aluno A: "Aperfeiçoamento."

Professor 1: "Aperfeiçoamento da técnica?"

Aluno A: (balança a cabeça positivamente) "Ele tá procurando uma forma mais prática, sem ter muito trabalho."

Professor 1: "Mas então quando que é tecnologia? Tecnologia é depois do computador pra frente?"

Aluna E: "Não."

Professor 2: "O que é que tá mudando nisso aí?"

Professor 1: "É, tem que pensar nisso aí, porque se vocês me disseram que a proposta tecnológica vai inovar a visão do trabalho e o aperfeiçoamento da técnica pode não inovar, pode manter, então nós precisamos saber o que que é essa tecnologia, pra saber então o que que nessas fábricas poderia ser feito. Vocês estudaram ontem a máquina a vapor. Ela foi uma técnica ou tecnologia?"

Aluno A: "Tecnologia."

Professor 1: "Por quê? Porque eu não posso encarar ela como forma do aperfeiçoamento do saber fazer? Eu fazia aquilo com a mão humana, eu 
aperfeiçoei aquela técnica criando algo que faz igual a mão humana, só que mais rápido." máquina."

Aluno A: "Mas é tecnologia, não é feito pelo homem, é feito pela

Aluna D: "Seria o que é feito pelo mecânico, não pelo humano, mas pelo mecânico, seria a tecnologia?"

Professor 1: "Algo não humano?"

Aluna D: "É."

Professor 1: "Mas criado pelo homem?"

Aluna D: "É."

Professor 1: "Ou algo não natural? Artificial, vamos dizer assim?"

Professor 2: "Por exemplo, ó: eu tenho dois celulares, um bem antigo e um novo. Eu aperfeiçoei a técnica ou a tecnologia?

Aluno A: "Tecnologia."

Professor 2: "Por quê?"

Aluno A: "Porque ele já tem um algo mais que o outro celular tem, é mais avançado..."

Aluna B: "O princípio é o mesmo."

Aluna D: "É, a técnica é a mesma."

Professor 2: "Qual seria a técnica dos dois? Falar? Eu continuei falando normalmente, só que esse aqui?" (mostra o celular mais novo)

Aluna D: "A tecnologia é mais avançada."

Professor 2: "Tecnologia avançada?" Então esse daqui deixou a minha vida, o que ele fez com a minha vida?"

Aluna B: "Facilitou. Eu acho que a tecnologia, ela facilita uma técnica. Facilita, ajuda, aperfeiçoa..."

Professor 1: "Mas o que a tecnologia exige do homem?...Pra se criar a tecnologia, o que que eu preciso? Isso tá tanto no exemplo do celular, quando da máquina que substitui o cara que tava lá trabalhando na caldeira."

Aluna B: "Eu acho que é o estudo."

Professor 1: "...Existe um problema, eu penso, ..., eu estudo, existe um campo de estudo, e aí nesse campo de estudo eu penso a solução pra esse problema, aí eu vou lá, aplico essa solução, aí eu vejo se ela deu certo ou não, eu avalio se ela deu certo ou não. E aí isso vai voltando sempre nesse movimento, né? Então, na verdade, para que eu pense tecnologicamente, eu preciso ter uma capacidade que é a capacidade projetiva. Ou não?

Aluna B: "Sim."

Professor 1: "O que é projetar algo? ... É pensar em algo antes dela acontecer...A capacidade projetiva segundo alguns estudiosos, ela está relacionada ao homem, né. Então, esse campo de estudo, esse cara que estuda, ele pensa esse problema, ele cria um mecanismo, um modelo, um sistema que facilite a vida dele, aperfeiçoando a técnica, muitas vezes ... buscando um avanço ... e depois ele avalia isso, isso pode consolidar ou não, isso chama tecnologia. Então se eu chamar a tecnologia da pilha de Daniel, se eu chamar a tecnologia da máquina a vapor. Alguém nessa revolução industrial escolhe a máquina a vapor como a tecnologia pensada pra um problema, que é o quê? Aumentar a produção. Isso rolou, deu certo, então manteve. E isso mudou a concepção de trabalho. 
As interações discursivas com os alunos finalizam com essa fala do professor.

Podemos observar que a sequência ocorreu como planejado e a participação dos alunos foi ativa, no entanto é possível notar mais participação no início, quando se discutia os contextos históricos, do que quando se discutiu sobre técnica e tecnologia, quando as falas começam a se voltar mais para exemplos de senso comum, o que era esperado, visto que o campo da tecnologia, ou a tecnologia como objeto de estudo não é uma abordagem comum nas escolas de ensino médio. Consideramos que reconhecer a tecnologia como algo artificial, estudado, projetado, produzido e avaliado pelo homem, e reconhecer a técnica como o "saber fazer", já consiste em um primeiro contato possível de assimilação para o público do ensino médio. Esperávamos poder ter introduzido também o conceito de ciência e ciência aplicada, o que, com certeza será buscado em aplicações futuras, visto que a própria discussão teve potencial para tal.

\section{CONSIDERAÇÕES FINAIS}

Consideramos que com a sequência didática proposta foram alcançados os objetivos de discutir os conceitos de técnica e tecnologia de maneira introdutória, dentro da dimensão que nos propomos a fazer, contextualizados historicamente pelo surgimento do capitalismo, reforma protestante e revolução industrial, mediante a controversa principal das diferentes concepções de trabalho de diferentes culturas religiosas. Quanto a interdisciplinaridade, não estamos certos de que podemos afirmar seu êxito, mas sim, sua busca, considerando, como Pontuschka (1993), a troca de idéias, os questionamentos, o estabelecimento e compreensão das relações entre os conhecimentos, a ampliação do espaço de diálogo na direção da aceitação de outras visões, e considerando também as relações estabelecidas entre a história e a tecnologia. Podemos assim, ou considerar a tentativa de interdisciplinaridade, ou a efetiva execução do que os PCNEM chamam de Ciências Humanas e suas tecnologias, no entanto, valendo-se dos conceitos de técnica e tecnologia como um fim alcançado por meio de contextos históricos culturais.

O leitor pode estranhar quanto a área curricular destinada à aula, ou seja, com ênfase em Ciências Naturais e sua real abordagem, a qual acaba por 
enfatizar as ciências humanas. No entanto, vale lembrar que se trata da primeira parte de uma aula de dois dias, sendo que no segundo dia a ênfase é dada ao conteúdo de combustíveis, com a química como componente disciplinar.

Esperamos ter contribuído de alguma forma para a busca de uma metodologia que preze pelo ensino e aprendizagem de maior qualidade no envolvimento dos alunos na aula e de uma aprendizagem mais significativa.

\section{REFERÊNCIAS BIBLIOGRÁFICAS}

BRASIL. Ministério da Educação (MEC). Secretaria da Educação Média e Tecnológica (Semtec). Parâmetros Curriculares Nacionais para o Ensino Médio. Brasília: MEC; Semtec. 1999.

CONSELHO NACIONAL DE EDUCAÇÃO. Parecer CEB número 15 de1 junho de 1998. Parâmetros Curriculares Nacionais. Relatora Conselheira Guiomar Ramo Mello; processo: 23001.0030. 72p. 1998.

LEVINSON, R. A Theory of Curricular Approaches to the Teaching of SocioScientific Issues. ALEXANDRIA: Revista de Educação em Ciências e Tecnologia. v.1, n.1, p. 133-151, mar. 2008.

LOPES, A. C. Parâmetros Curriculares para o Ensino Médio: quando a integração perde seu potencial crítico. In: Macedo, E. (Org.). Disciplinas e Integração Curricular, História e Políticas. Rio de Janeiro: DP\&A, 2002. p. 145-175.

LUCKESI, C. Avaliação da Aprendizagem. Série Encontros. [Filme-vídeo]. Produção por Paulo de Camargo. Março/2012, 1:22:36, color. Som. 2012.

PONTUSCHKA, N. (Org.). Ousadia do diálogo. São Paulo: Loyola, 1993.

REIS, P. R. Os Temas Controversos na Educação Ambiental. REVIPEA Revista Pesquisa em Educação Ambiental. Vol. 2, n. 1, p. 125-140. 2007.

RICARDO, E. C; CUSTÓDIO, J. F; REZENDE JR, M. F. A Tecnologia como referência dos saberes escolares: perspectivas teóricas e concepções dos professores. Revista Brasileira de Ensino de Física. Vol. 29, n. 1, p 135-147. 2007.

SADLER,T.D; FOWLER, S.R. A Threshol Model of Content Knowledge transfer for Socioscientific Argumentation. Wiley Interscience. 2006. 